\title{
Ssciendo
}

Ethics \& Bioethics (in Central Europe), 2021, 11 (1-2), 82-91

DOI:10.2478/ebce-2021-0010

\section{Stoic pragmatist ethics in the time of pandemic}

\section{Krzysztof Piotr Skowroński ${ }^{1}$}

\begin{abstract}
The present paper is a response, of sorts, to the challenges of the coronavirus pandemic (COVID) and lockdown that we all must face. We have an idea of what doctors, nurses, teachers, among many of the other professions, do for the general public, but one may ask whether there is something substantial that philosophers and ethicists can offer in these circumstances. The thesis of this paper is that the stoic attitude towards times of trouble and the pragmatist way of finding out what is possible to elevate the quality of living against all odds, if skilfully interwoven, could be an important tool in keeping mental health in good shape and, additionally, could contribute to the cultural scene at large. If this is the case, stoic pragmatists can indeed offer an interesting example of practical philosophy for many audiences, especially during the pandemic lockdown and, perhaps, for other serious difficulties or problems. To be effective in delivering their message, stoic pragmatists, as most with philosophers today, should enrich their textual and oral modes of traditional transmission of knowledge and become digitalculture public intellectuals that can recognize and reach more general audiences by, among other things, visual modes of digital communication.
\end{abstract}

Keywords: stoic pragmatism, ethics, pandemic, digital culture

\section{Stoic ethics and pragmatist ethics: Any points in common?}

There must be something exceptional in Stoic ethics (in this text, capital "S" refers to the historical Stoicism, small "s" to its contemporary trajectories, and "SP" to stoic pragmatism). It is as if there were an invariable lode of wisdom within the orientation that has stood the test of time. It has had a continuing relevance long after its classic representatives died, and long after their ideas reappeared in medieval Christianity and the Renaissance. In the modern age, it has been inspirational even when deprived of some of its original metaphysical ingredients. Recent decades have not been that much different. There have been numerous scholarly studies (Irvine, 2009; Brouwer, 2014; Holiday, 2016; Pigliucci, 2017) that have assumed the general name of New Stoicism or Modern Stoicism. One of the principal figures of this movement, Lawrence Becker, interprets Stoic themes from a contemporary perspective as if Stoicism has had a continuous history up to the present, and that some of its themes have developed according to the successive developments of physics, logic, and ethics (Becker, 1998/2017, pp. xii-xiii). At the same time, some elements of Stoic ethics are incorporated into different contemporary contexts that lie outside of academia: business, coaching, leadership, mental hygiene, and many other enterprises and platforms. Numerous blogs and websites dedicated to Stoicism that can be found on the Internet testify to this. The question arises how one can adapt Stoic teaching into contexts of our present situation, scantily metaphysical and with so much of it secularized and commercialized. Becker answers that a part of Stoic ethics, in opposition to Stoic cosmology and theology, can be easily adapted nowadays, if "appropriately restated". He even claims that "Stoic virtue ethics could have remained largely the same" as would the idea of "living in accord with nature" and other central doctrines of historical Stoicism (Becker, 1998/2017, p. xiii).

Interestingly enough, there have also been attempts to merge Stoicism with the philosophical tradition of American pragmatism in recent years. Frank McLynn (2009) in his biography of Marcus Aurelius, writes about Marcus's pragmatic approach to public works and generally takes Stoicism as a primitive version of pragmatism. Ethically speaking, he claims, "Stoicism

\footnotetext{
${ }^{1}$ University of Opole (Poland); skris65@gmail.com; ORCID: 0000-0003-3814-1346
} 
was a primitive form of pragmatism, in that one knew in advance that the value of duty would always overrule that of pleasure, and strenuous virtue that of lazy indolence or apathy" (McLynn, 2009, p. xvi). From the political angle, he describes Marcus as a "political pragmatist" (McLynn, 2009, p. 185) and offers a more general comparison: "Pragmatism in the U.S.A. functions as an ideological 'support' for the social and political system, just as Stoicism did in Roman society (...). Stoicism and pragmatism are both 'imperial' ideologies, both suited to world powers at the moment of their greatest dominance" (McLynn, 2009, pp. xiv-xv).

Stoic pragmatism (SP), which I address below, embodies the ambition to be a more developed version of interpreting these two philosophical traditions from the point of view of their common individual and public aims. That pragmatism emphasizes the social context of the individual life is no surprise given the abundant efforts of some its classical figures $(\mathrm{G}$. H. Mead, John Dewey, Sidney Hook) to examine this relation and stress the social and cultural impact on the individual. The Stoics, however, have a notorious reputation in popular circles of having been egocentric individuals indifferent to what happened around them. Yet, they did refer to social contexts and some of the basic ideas of their doctrine (oikeiosis, kosmopolites) have a strong social-ethical character. Some Stoics held public responsibilities and referred to the social aspects of their purposive actions, in the strong sense of Marcus Aurelius's claim that "rational beings exist for one another" (Marcus Aurelius, book IV, chapter 3). Hence, the temptation for the stoic pragmatists to wed these two sources together and put forward a concept that would focus on meaningful life individually and, at the same time, strengthening it by giving it a public and cultural significance.

\section{What is Stoic pragmatist ethics?}

The term stoic pragmatism was coined by the Hungarian-American philosopher John Lachs (2005; 2012; 2014a; Skowroński, 2018), as a theory and practice of the good life both in individual, social, and cultural contexts. The present text, as well as some others (Skowroński, 2020a; 2020b) complement and develop Lachs's initial idea, and the reasons why I want to do it are the following: It seems to me that our (my own and Lachs's) Eastern-European postCommunist sensitivity renders us similar on two points. First of all, to have experienced what it means to have very little is an excellent way to appreciate what the wealthy, liberal West can offer, even during dire crises. Secondly, this appreciation needs to be assisted by learning how to use this wealth and liberty, intelligently and in an enjoyable manner, rather than to complain about not having more.

SP has two principal philosophical sources of inspiration. The first is American pragmatism, especially James, Dewey, Royce, and Santayana, whose links with pragmatism are detectable at some points. The second is the philosophy of Stoicism, especially the ethics of the Roman Stoics: Epictetus, Marcus Aurelius, Seneca, who in some places "is indistinguishable from a pragmatist" (Lachs, 2012, p. 47), and Cicero who, fundamentally, was more a sympathizer of Stoicism and an elaborate articulator of its ideas rather than an authentic Stoic philosopher. In his own works, Lachs reduces the whole tradition of Stoic philosophy to its later, Roman, version in which, as in the pragmatism of James and Dewey, metaphysics was much less pronounced than ethics: "The heart of stoicism is its ethics, not its metaphysics or epistemology" (Lachs, 2014a, p. 203). Despite many unquestionable discrepancies between these two important, yet historically distant, philosophical traditions, an effort to "enrich and complete each other" (Lachs, 2012, p. 5) finds its justification in providing "a better attitude to life than either of the two views alone" (Lachs, 2012, p. 42). As a result, "Stoic pragmatists believe that intelligent effort can make life longer and better. At the same time, they acknowledge human limits and show themselves ready to surrender gracefully when all efforts at amelioration fail" (Lachs, 2014a, p. 206). 
Stoic pragmatists hope that if we interpret pragmatically some of the Stoic ideas (which are also Hellenistic on some points) that refer to the good and meaningful life, and practically weave them into contemporary contexts, that they make it possible to help us recognize our own sense of agency in a more effective way, and this in order to increase our sense of the quality of our lives, which is also one of the ways to ameliorate social life. For example, "The most notable feature of pragmatists is their commitment to bring life under intelligent and effective human control" (Lachs, 2012, p. 44). This does not differ much from the Stoics, at least in using a rational selection of things and actions that help them control the self and become self-sufficient. Becker also, as already mentioned, has indicated that, for modern stoicism, rational agency "is a defining feature of mature human consciousness" (Becker, 1998/2017, p. 13).

We could anticipate that if such an attitude towards life were to become a more popular stance, it could lead to an amelioration of social life, and a modification of culture in a variety of ways. The assumption for this claim being that a way to make social and cultural life better is through the moral and cultural betterment of the members of the group; in the same way, the betterment of institutions can be achieved by the betterment of the members of these institutions, and the term "betterment" in SP means, among other things, individually assuming a better attitude (more effective) in reference to such aims as the quality of life and its meaningfulness in various contexts. Dealing with the coronavirus pandemic lockdown is one of such contexts, and on this point, I update Lachs's original idea of SP. In the context of a pandemic, the principal idea of SP would be to use these two philosophical sources so as to form a sort of approach toward life by strengthening the individuals and giving them a more efficient orientation toward their current situation, and more optimal ways of self-development against all odds.

SP is an open project in the sense that it pursues factual improvement in the quality of life for living individuals, rather than a new theory about such improvement. It hopes to do it by showing, explaining, and encouraging better attitudes towards life among various audiences, despite divergent cultural norms and clashing values. SP abandons "the research/discovery paradigm of philosophy" as "wrongheaded and unproductive" (Lachs, 2012, p. 21) and focuses on the expansion of philosophy beyond the practices of academic circles out into the open public. Stoic pragmatists should be instrumental in giving (and justifying) the patterns and strategies of the good life, be they individual, social, or cultural, yet they do not and cannot solve problems in a scientific or political way. Stoic pragmatism does not and cannot solve the problem of the pandemic, yet it can help us think about what to do during a difficult time. More generally, it is hardly possible to overcome problems that are out of our reach, yet we can optimize our efforts within what is possible, according to Santayana's general claim that "survival is something impossible: but it is possible to have lived and died well" (Santayana, 1951/1995, p. 210).

SP should promote philosophy understood as a guide to life for many audiences rather than a methodologically coherent set of theories for a limited circle of experts. There are even places in which Lachs uses, as did the Stoics, the analogy between medicine (treatment of the body) and philosophy (treatment of the soul). On the other hand, the present hyper-professionalization of science-oriented philosophical research that makes philosophy look abstract and superfluous for the general public is Lachs's main criticism of contemporary philosophy and seems to be the main reason why he proposes his idea to wider audiences. SP can be seen as, at least partially, a result of Lachs's critical assessment of American pragmatism. Especially, that it was pragmatism that announced a transformative model of doing philosophy as a practical amelioration of society and its culture. However, it has failed to do so by having become entangled in a web of meticulous analyses of abstract puzzles. Having been unable to offer an adequate attitude towards life, it requires "a stoic correction" (Lachs, 2012, p. 56), that would 
make pragmatism more practical and action-oriented and more widely audience-oriented. Despite praxis being announced as the central theme in pragmatism it is, in fact, the idea of praxis or the theory of praxis that is discussed most profoundly in the pragmatist camp. Despite James's moral message to evoke "energies of men" as well as Dewey's appeal to deal with the problems of people rather than those of philosophers, a great part of the work that pragmatists take on deals with exchanging views about theoretical issues among professors and candidates for professorships within academic institutions. This combination of theorizing and elitism has resulted in abstract hairsplitting presented in sophisticated argot barely understood by anyone outside of academia and having little impact on the cultural world. Whereby, if members of the public should need or hope for anything from philosophers at all, it is not new theories rendered in technical language about problems that hardly anyone outside of academia would see as important. As a consequence, we witness a growing abyss between philosophy and wider audiences for whom philosophers and their work seem both abstract and irrelevant. It is not the fault of these audiences, but that of the philosophers themselves because they seem not to care or forget that "philosophy becomes marginalized only when it distances itself from the problems of life" (Lachs, 2003, p. 11). At this very moment, the coronavirus pandemic is the existential problem that philosophers, stoic pragmatists or not, should address and come to grips with.

\section{Stoic pragmatist diagnosis of contemporary Western culture}

The term "diagnosis" is not used here to claim that Western culture is ill, but to show SP's therapeutic ambitions in identifying problematic contexts, such as the pandemic for example, and convert them into challenges while suggesting a possible "treatment", or a possible way out in the form of appropriate actions, of which I write below. At the same time, the phrase "Western contemporary culture", indicates the operational framework for SP, but is difficult to define precisely: it includes the Antipodes (Australia and New Zealand) and excludes, say, Cuba, Haiti, and Venezuela, despite the fact that they are in the Western hemisphere. Additionally, we have millions of migrants (or their parents) who have arrived from Asia or Africa and now live in Western countries and whose characterization as being "Western" tends to be ambiguous. Moreover, we have many non-Western countries that have implemented and even integrated some elements of Western culture into their social fabric, and are "Westernized" to some extent - Taiwan having recently legalized same-sex marriages, for example.

Nevertheless, Western contemporary culture can be characterized collectively, without specifying numerous types of more specific traditions, cultures, and subcultures that constitute it. Viewing it from the stoic pragmatist perspective, we can say that one of its main features is that it provides a relatively high level of comfort for a major segment of its population, along with many types of opportunities that may make our individual lives more meaningful and our collective life more or less functional. Excluding this terrible span of time of the coronavirus pandemic, it has been a considerably peaceful time with no wars amidst the West in recent decades, with the most open accessibility to education ever attained, the highest living standard for a major part of the population, the highest life expectancy, the most developed social security system available to a major part of North Americans and Western Europeans, and with social justice systems that are more developed than in other places in the world right now, and more than in the past.

This does not mean at all that social justice is guaranteed or that there are no conflicts among numerous social groups, but there is a hopeful prospect, in general, for everybody's future. Nor does it mean there are no clashes among social groups with specific interests, or societal problems related to ethnicity, race, religion, politics, sex, gender, and, perhaps most importantly, an economic gap between the superrich elite and the poor. Yet, SP claims that some balance and adequate assessment must be exercised in our criticism of situations and it 
needs to be taken into consideration that there have never been conflict-free societies. Additionally, if we look at what is happening and has happened elsewhere, contemporary Western culture provides most of its members comparatively advanced forms of individual and communal possibilities for thriving and self-realization in relatively numerous areas of life. One of these ways of thriving and self-realization is the recognition of different modes of cultural life, many of which have been emancipated on an unprecedented scale in history. Latin America, Africa, Asia, and Russia do not provide such a scale of autonomy, social security or freedom for vast segments of their societies. Nor do we know of any societies in history, including the first democracy in ancient Greece, full of slaves, that has developed a comparatively decent and secure system for most of its citizens.

All these achievements - and this is the other part of the characterization of Western culture - do not seem to get easily converted into a commonly enjoyed sense of a meaningful life, as if the already available sources and opportunities were, for whatever reasons, unrecognized and unused by a significant segment of the Western population. This unrecognition of what we have, among other things, produces unnecessary disappointment, frustration, and a sense that life is meaningless and full of conflicts. Some of those negative reactions have burrowed even deeper during the coronavirus pandemic.

An adequate assessment requires comparisons and proportions, without which it is difficult to maintain any orientation points. Making comparisons with other cultures, present and past, to assess our situation is both pragmatic and stoic; pragmatic because it actually shows us the current state of our culture in light of its achievements and failures, and stoic because it distances us from those conventional fashions that assess cultures, ours or others, in simplistic, black-and-white, and absolutistic terms. Such comparisons should accommodate the already incredibly rapid accelerating progress of the medical and hygiene industries, along with access to medical knowledge via the Internet to practically everybody. This also includes the coronavirus pandemic. Obviously, this is a great tragedy and the millions of people affected should spark concern in everybody. At the same time, there are some options for us and recognition of these options and acting on them accordingly is something that we can do.

\section{Appropriate actions in the context of the pandemic (and similar troubles)}

"Appropriate actions" (Lachs, 2012, p. 45) try to link the pragmatist idea of intelligent action, especially Dewey's “intelligence as the preferred method of action” (Dewey, 1933, p. 101), with the Stoic kathekon or officium (Cicero, 1918, p. 409), although without the metaphysical background of the latter. Stated otherwise, appropriate actions, in the stoic pragmatist interpretation, refer to what rationally should be done or chosen in any given circumstance and in legitimate respect to the regularity of nature, as it so happens, for example, when one reflects on what should be done to maintain good health, corporal and mental, for the longest time possible, while trying to take into consideration the various natural and cultural factors of diet, hygiene, physical activity, as well as the consequences of one's decisions to forego them. We do not have unlimited choices and cannot have control over the entirety of the external world; sometimes such choices are indeed limited. However, we can focus on what we can do by, initially, becoming aware of the choices that surround us. In our contemporary world, in opposition to the views of so many critics of Western culture, there are opportunities and accessible goods that were unimaginable by the generations who lived before us.

This includes all sorts of medical, hygienic and therapeutic sources of information accessible by the Internet at no cost. Most importantly, however, this includes access on the part of individuals to national health systems. The degree to which accessibility by a significant portion of a country's population to first-rate health-care has never been equal to what it is today. Ignoring these factors would be neither rational nor appropriate. Just having our awareness more heightened may make it possible to become cognizant of the amount of salutary social 
wealth surrounding us, and the ways of dodging malevolent influences. SP stresses the autonomous agency of each of us in this respect.

SP claims that "each private, conscious person is a unique center of activity and feeling" (Lachs, 2019, p. 7). The SP attitude includes, among other components, the Socratic "know yourself" idea of self-knowledge, which refers to our own possibilities; however, these possibilities should always be contextualized and inevitably be based on, for example, the knowledge that we can derive by using different sources. The recognition of one's singularity (know yourself) as well as that of others (humanism), does not allow stoic pragmatists to immerse uncritically into a surrounding culture or cultural fashions, nor does it allow them to fall into victimization narratives about their fate or fatum. Actually, it is our own choice to collapse or not to collapse into victimhood narratives. Epictetus, a former slave, physically disabled, and even then a renowned teacher of how to attain happiness (eudaimonia), stands as an iconic figure in showing us that a meaningful life depends on our attitude and on our character, much more than on surrounding conditions: socio-political, economic, and historical. The proto-pragmatist (Ralph Waldo Emerson) spoke to the idea of a self-made man. The pragmatist reference to meliorism, and, for the first time in history, unlimited access to knowledge (through the Internet), which makes it possible for us to become more aware of the possibilities of thriving, help to update the claim about the vital importance of attitude towards the surrounding world.

Multiple forms of appropriate action that use tools and skills that are readily at hand according to the claim that the more self-knowledge one possesses, the better are the actions that one performs. That is, they do not require substantial or additional funding, and they are realizable on our own, at practically any moment of reflection, and they start in our minds which means the realization of them does not depend completely on external circumstances. In this way, we pragmatically realize particular activities in order to achieve given aims and, stoically, we depend primarily on our decisions and our recognition of situations rather than on the external circumstances. To be sure, we must take them into consideration as we must take into consideration the weather conditions when we want to go outdoors. However, this does not entail that we depend on them in the same way as when grabbing an umbrella to not get wet, or an overcoat to not suffer cold, as we protect ourselves against the elements while simultaneously realizing our intended plans, notwithstanding those elements.

Does SP have any message concerning an individual's strategy in relation to the people encompassing one? The Stoic idea of oikeiosis, or Hierocles's concentric circles, as transmitted by Stobaeus (Whittingham, 1822), corresponds with the stoic pragmatist virtue of leaving others alone (Lachs, 2014b). Concentric circles, as when a stone is thrown into the water, show the center of attachment, affection, and vital interest that every individual should zero in on and take care of; yet, at the same time, his or her social bonds decrease to the extent that circles expand outwards. The closest circles would include one's relatives, then one's community, then one's culture, and finally all of humankind. Nevertheless, with the least possible amount of attachment do we fulfill this. The idea does not evoke egotism in the sense of a detached selfinterest and insensitivity or indifference to the fate of others. Rather, it means that there is a natural order of things, that individuals are the basic points of reference in their actions, that there is a degree of responsibility for others, and the degree is more acute when we deal with those closest to us. Those others who are around us should be helped when needed; however, when they do not need our help, we should be wise and tolerant enough to let them do what they think proper for themselves.

\section{Marcus Aurelius's message on the pandemic in 165-180 CE}

In the later years of Marcus Aurelius's life, a terrible plague spread within the Roman Empire in the years 165-180 CE. The so-called Antonine Plague, probably caused by smallpox or 
measles, caused the death of between 5 and10 million people (according to World History Encyclopedia). Interestingly, the time of the pandemic (in the years 165-180) coincided with the time of his composing Meditations (161-180). In point of fact, his short collection of thoughts addressed to himself do not focus on the pandemic, despite the fact that, relatively speaking, it was far more devastating that our current pandemic, Covid 19. Perhaps the pandemic, the military campaigns and the battles, and the harsh material conditions of social life all together comprised a cultural and intellectual ambience in which only good character (virtue, the Greek areté) was capable of being the stable and reliable point of reference. How do we interpret his claim that the plague, or "mental cancer", understood in the moral terms of "dishonesty, or hypocrisy, or self-indulgence, or pride" is "worse than anything caused by tainted air or an unhealthy climate? Diseases like that can only threaten your life; this one attacks your humanity"? (Marcus Aurelius, book IX, chapter 2). Is this an informative message for us today?

We should not forget that the Stoics did not live in a capitalist society and did not develop a consumerist mentality. This may be one of the reasons why their message about temporary goods sounds strange to contemporary ears, especially in the West. Yet, it was not a message about asceticism and the rejection of goods that was pronounced most strongly, but rather a message about controlling our approach towards objects (material goods) and states of affairs (natural and social phenomena) in other words things that cannot be effectively controlled by us. In other words, we should do what is within the powers of our will and our intellect to make our lives better, but it is very risky and unpredictable for ourselves if we make the external world - external in relation to what we can do - the main point of reference.

Yet, we have a problem at this point. The external world, to which the Stoics recommended a sort of emotional disengagement (apatheia), embraces the contemporary health service, medical technology, the Internet full of medical expertise, our educational systems and so onafter all, these are the externals against which the Stoics warned us. Here, it seems to me, that the message of historical Stoicism should be updated, for example, by the pragmatist approach according to which the modern achievements of the Western world should be appreciated and taken seriously. I say appreciated, not uncritically indulged. This also refers to the ways in which stoic pragmatists should disseminate their philosophical and ethical message which, in our time, needs to be delivered via the Internet and social media so as to more effectively reach as big an audience as possible.

\section{Digital-Culture as public intellectual activity}

I would like to get back to responsibility. More specifically, not of everyday inhabitants of the public realm, but that of the philosopher and ethicist, stoic pragmatist or not. One of the ways to cope with the challenges I write about would be becoming a digital-culture public intellectual. Such an intellectual would have to, among many other things, modify and broaden the traditional modes of communication. Namely, such an intellectual would have to expand his or her textual or primarily text-related communication mode into an aesthetic and visual communication mode. More precisely, stoic pragmatists would have to learn how to aestheticize and visualize their ethical and cultural narratives by using some digital tools, YouTube clips for example. If we want to stress the role of reflection in the quality and meaningfulness of individual lives, or if we want to try to self-develop during lockdown, we cannot just talk about it in a (digital) classroom or merely write scholarly papers about it; we should also be able to display it in an attractive way so as to be more convincing to various audiences. Why is this important?

Whether philosophers and ethicists should stay in university classrooms and congress conference rooms, or move their activity onto the Internet, does not seem a yes/no dilemma any longer. Institutions of higher education in the West have been losing their privileged status, if 
not monopoly, as exceptional institutions that are responsible for the cultivation and transmission of knowledge to future generations. The Internet, independently of any university curricula, stores and transmits knowledge and wisdom in whatever area the learner wants to choose and does it on a much larger and much more accessible scale than institutions of higher education. Even well before the present lockdown, very few students had their hands Smartphone-free, and they had already been deeply affected by the technological transformations in what they think and what they do. During the current lockdown period, the processes of the digitalization of education accelerated even further, and as a result, we can surmise, Western academia will never return to its traditional shape. If so, intellectuals, stoic pragmatists or not, should creatively use available digital tools to be actively present in cyberspace so as to shape its content. Or, at least, they should want to try to do it and have some intention to make a slight difference in the character of the thoughts and ideas to be accessed on the Internet. Many of our university colleagues perform this or that form already with a various spectrum of tools.

Would we be able to define or specify this type of activity? Elsewhere (Skowroński, 2020a), I have tried to propose a definition that would embrace stoic pragmatist philosophers' and ethicists' activity in cyberspace as an array of practices that explore digital tools to make philosophical, ethical and values-oriented messages be recognized by wide audiences. This definition stresses, first of all, the role of practices that would enable digital-culture public intellectuals to produce the material and introduce it into cyberspace. I mean not only to the technical activities but even more importantly to the social practice that is essential to such philosophical traditions as Stoicism and pragmatism (and possibly some others) with their focus on practical action of a given individual for the sake of social amelioration. Secondly, it stresses the role of recognition of the message by the target audience. Just putting the material out into cyberspace can hardly make any difference, as we have an ocean of materials already existent. Publishing a text on a personal website may result in nothing more than a short-time action and even shorter-time reaction of the viewers, with the text and its ideas remaining unseen by the larger public, and having no impact whatsoever on anyone. Instead, the recognition of the public intellectual's message is closely related to the public intellectual's recognition of the audience to which the message is directed, and the manner of communication in which this message is conveyed. This is why, thirdly, digital-culture public intellectuals, especially those of a pragmatist sensibility, should be predisposed to recognizing the communication needs and expectations of various audiences, given pragmatists' focus on anti-essentialism pluralism, toleration, and contextualization. The biggest challenge here is that there are many target audiences, and the modes of communication differ from target audience to target audience. Many non-academic audiences are non-textual-culture oriented, and they understand communication best when visual elements of certain sorts play the central role. This happens in the case of a massive audience, and, in my view, public intellectuals, philosophers included, need to take it into consideration.

\section{Possible criticism of SP on the virtue ethics vs utilitarian ethics inconsistency}

The question of the integrity of stoic pragmatist ethics can arouse controversy. One can say that SP is internally split because its two components refer to divergent types of ethics. Both historical Stoicism and contemporary stoic moral ideas refer to virtue ethics, whereas pragmatism has its roots in utilitarian ethics. According to the former, it is the character of the person that needs betterment independently of the external circumstances and this very character is the main source of tranquillity (ataraxia) and happiness (eudaimonia). Virtue (arete) should be cultivated for its own sake and possible cultural pressure from surrounding social conventions should not be taken as an indicator of the virtue's worth. Nor were various cultural norms seen, at least openly, as sources for enrichment for a Stoic because virtue (arete) 
was something internally given, not externally, that is to say from a contingent form of culture. According to the latter, the good is measurable by the fulfilment and satisfaction that most members of the group can derive from any given activity. The cultivation of any personal virtue that is not transmissible to other members of the group does not deserve any special status. Nor it is possible to cultivate one's own private virtue, because moral standards are social and cultural products.

Such a division between these two, however, although interesting theoretically, does not have to look so divisive in the practice of life. Those Stoics who had public roles, like Marcus Aurelius and Seneca, could not limit their ethics merely to perfecting virtue only. They knew very well that they had to act meaningfully in social, political, and cultural contexts, in the name of the common good. It was simply necessary to execute their public functions in a proper, if not a pragmatic way. This type of interpretation, among other possible ways of dealing with the virtue ethics vs. utilitarian ethics discrepancy, can be seen, for example, in Bertrand Russell's History of Western Philosophy. According to him, the Stoics worked out double standards, or rather, two standards of narrating what is good and bad: one for themselves and another standard for non-Stoics. Russell explains these two standards by establishing a context of economic activities or, as we would say today, business life. The first part of his statement deals with the Stoic attitude:

When the Stoic philosopher is thinking of himself, he holds that happiness and all other worldly so-called goods are worthless; he even says that to desire happiness is contrary to nature, meaning that it involves lack of resignation to the will of God. But as a practical man administering the Roman Empire, Marcus Aurelius knows perfectly well that this sort of thing won't do. It is his duty to see that the grain-ships from Africa duly reach Rome, that measures are taken to relieve the sufferings caused by pestilence, and that barbarian enemies are not allowed to cross the frontier (Russell, 1946-1947, p. 291).

The second part of Russell's statement speaks about the two different Stoic approaches towards economic reality:

...in dealing with those of his subjects whom he does not regard as Stoic philosophers, actual or potential, he accepts ordinary mundane standards of what is good or bad. It is by applying these standards that he arrives at his duty as an administrator. What is odd is that this duty, itself, is in the higher sphere of what the Stoic sage should do, although it is deduced from an ethic which the Stoic sage regards as fundamentally mistaken (Russell, 1946-1947, p. 291).

It seems that Russell's interpretation can be helpful in dealing with the virtue ethics vs. utilitarian ethics discrepancy. This interpretation can also be helpful for stoic pragmatists to work on more efficient communication with their audiences.

\section{Conclusion}

I do not suggest that philosophers and ethicists should become stoic pragmatist philosophers; nor do I suggest that public intellectuals can significantly shape the content of social media and have an impact upon a mass popular audience. I do not have such hopes because I follow the Stoics' claim that the external results of actions are out of our control and, therefore, should not be the main concern. What is within our, philosophers' control, and pragmatist at the same time, is to propose a vision of the good life for us and those who want to listen, a vision that would refer to the most important issues of the day. Coronavirus and the lockdown belong to such issues. Stoic pragmatists cannot be invisible in the public debate on such problems because they 
know very well that "philosophy becomes marginalized only when it distances itself from the problems of life" (Lachs, 2003, p. 11).

\section{References}

BECKER, L. C. (1997/2017): A new Stoicism. Revised Edition. Princeton \& Oxford: Princeton University Press.

BROUWER, R. (2014): The Stoic sage: The early Stoics on wisdom, sagehood and Socrates. Cambridge: Cambridge University Press.

CICERO, M. T. (1918): Letters to Atticus, vol. 3, trans. E. O. Winstedt. London: Heinemann. DEWEY, J. (1933): Later works, vol. 8, ed. J. A. Boydston. Carbondale: Southern Illinois University Press.

HOLIDAY, R. (2016): The daily Stoic: 366 meditations on wisdom, perseverance, and the art of living. London: Profile Books.

IRVINE, W. (2009): A guide to the good life: The ancient art of stoic joy. Oxford: Oxford University Press.

LACHS, J. (2003): A community of individuals. New York \& London: Routledge.

LACHS, J. (2005): Stoic pragmatism. In: Journal of Speculative Philosophy, 19(2), pp. 95106.

LACHS, J. (2012): Stoic pragmatism. Bloomington and Indianapolis: University of Indiana Press.

LACHS, J. (2014a): Was Santayana a stoic pragmatist? In: M. C. Flamm, G. Patella \& J. A. Rea (eds.): George Santayana at 150: International interpretations. Plymouth: Lexington Books, pp. 203-207.

LACHS, J. (2014b): Meddling: On the virtue of leaving others alone. Bloomington: Indiana University Press.

LACHS, J. (2019): The cost of comfort. Bloomington: Indiana University Press.

MARCUS AURELIUS (2003): Meditations, trans. G. Hays. New York: The Modern Library. MCLYNN, F. (2009): Marcus Aurelius. A life. Boston: Da Capo Press.

PIGLIUCCI, M. (2017): How to be a Stoic: Using ancient philosophy to live a modern living. London: Rider.

RUSSELL, B. (1946/1947): History of Western philosophy and its connection with political and social circumstances from the earliest times to the present day. London: George Allen and Unwin.

SANTAYANA, G. (1951/1995): Dominations and powers: Reflections on liberty, society, and government. New Brunswick \& London: Transaction Publishers

SKOWROŃSKI, K. P. (ed.) (2018): John Lachs's practical philosophy: Critical essays on his thought with replies and bibliography. Leiden \& Boston: Brill/Rodopi.

SKOWROŃSKI, K. P. (2020a): Philosophy in digital culture: Images and the aestheticization of the public intellectual's' narratives. In: Eidos: A Journal for Philosophy of Culture, 4(1), pp. 23-37.

SKOWROŃSKI, K. P. (2020b): Santayana as a stoic pragmatist in John Lachs's Interpretation. In: Overheard in Seville: Bulletin of the Santayana Society, 38, pp. 109-123.

WHITTINGHAM, C. (ed.) (1822): Political fragments of Archytas, Charondas, Zaleucus, and other ancient Pythagoreans, preserved by Strobaeus, and also ethical fragments of Hierocles, trans. T. Taylor. Chiswick, UK. 